\title{
Equity Valuation Approach Based on Accounting Variables
}

\author{
Thanakornn Phansawadhi* \\ Faculty of Engineering, Khon Kaen University, Khon Kaen, Thailand \\ *Corresponding author:thanakornn@kku.ac.th, thanakornn@gmail.com
}

Received April 16, 2013; Revised May 18, 2013; Accepted May 19, 2013

\begin{abstract}
This academic paper proposed theoretically the alternative estimate of the cost of equity capital (COE) for accounting-based residual income model (RIM), which this quantity becomes an important variable for the intrinsic worth valuation model. Its format can be express interchangeably in many forms of accounting variables combining with some financial ratio. The basic assumption is relying on that the quantity of COE for an asset should reflect from its profitability and change in market price during given periods. By taking reverse-calculation into the particular RIM equation, these outcomes (alternative COE estimates) are consistent according with the fact that the investors reasonably expect to earn from investing in shares of a firm through both or either total dividends and prospective increment in market capitalization. The proposition can be eliminating the lacked explanation of existing estimates and also explainable why investors are still investing in shares of a firm that has no dividend policy. While traditional estimation methods default the explanation of this truth.
\end{abstract}

Keywords: cost of equity capital, discount rate, equity valuation, intrinsic worth valuation approach

\section{Introduction}

In finance, the stock valuation approaches are the method of estimating the fundamental values of the firms and their common stocks. Several approaches based on accounting and financing have been developed over a long period of time. The discounted cash flow (DCF) model is popularly a technique of equity valuation, which is used to estimate the attractiveness of an investment opportunity. However, all approaches of equity valuation are significantly affected by the investor's required rate of return on the common stock because this rate becomes the discount rate or to be a main component of the discount rate. That is possible to derive prosperously the intrinsic value above or below current market prices depend on the estimated discount rate and the measurement of cash flows or dividends.

DCF techniques are obvious choices for valuing the intrinsic worth because they are attempting to evaluate through the present value of expected cash flows. The main difference between the alternative approaches is how one specifies cash flow or measures the used cash flow. The cleanest measure of cash flow is "dividends" because these are clearly cash flows that directly go to the stockholder, which implies that analyst should use the cost of equity financing as discount rate [1].

The dividend discount model (DDM) is very useful when discussing valuation for a stable, mature entity where the assumption of relatively constant growth is appropriate for the long term. However, this technique is quite difficult to apply into the firms that have no dividends policy during the periods of high growth, or currently pay very limited dividends. Ohlson (1992 \& 1995) was introduced to the residual income model instead of the dividend discounting valuation model (the same conceptions appearing in Edwards and Bell, 1961), which specifies the relation between equity values and accounting variables such as book value, net income, and earnings [2,3].

This study focused on the discounted residual income (or Edwards-Bell-Ohlson: EBO) valuation, which is the most effective model of DCF valuation approach. The purpose of this study is to determine the cost of equity (COE) for the accounting based residual income valuation, which is an important variable for the equity valuation. An alternative proposition of COE estimate is to expel the arguments in traditional method by emphasizing the relationship of dividends and investment behaviours. Continuously, this proposition is to introduce the ways of private company valuation which one is concerning to the cost of equity financing (COE) when the market values of that firm are available, and the other is based upon the return on equity (ROE) when the market values are unavailable. Therefore, the intrinsic worth valuation can be applied for evaluating other assessments such as measuring the profitability performance of divisions, projects, and assets as well.

\section{Literature Reviews}

The linear information dynamic originally proposed by Ohlson (1995) but it is worth mentioning that this dynamic need not be linear. The linear information dynamic has acknowledge under the increased scrutiny since its inception and there appears to be significant 
evidence that have several attempts to develop the model utilizing non-linear information dynamics. Whilst the linear information dynamics allows for a parsimonious accounting valuation to be modeled, many authors have apparently struggled with its constrictive nature leading to modifications that have created internal inconsistencies [4]. Example of these papers had reported by Ref. [5,6,7] which provide the excellent reviews of the EBO model and empirical support for the decay of abnormal earnings, their implementation of the $E B O$ model potentially harms the subsequent empirical tests of the model that they performed (Dechow et al., 1999). Their performances are robust for discount rates in the range of nine to fifteen percent that given it is known that risk varies by firm; a more realistic representation of risk would be reflected by using firm-specific risk (Beaver, 2002). Furthermore, given that risk has a pivotal role in the $E B O$ model, which it appears to be an oversight not to attempt a more accurate representation. Despite of these criticisms, Dechow et al. found very limited support for the linear information dynamics.

Callen and Segal (2005) reported that something missing from the previous studies reviewed so far is that they lack a realistic operationalization of the "other information" variable. This paper would be expected to affect abnormal earnings, while would not perhaps reflects the most informative variable for this purpose. In summary, [8] find more positive evidences to support the EBO model.

Various empirical researches have typically provided enthusiastic support to the accounting-based residual income model, consistent evidence that the residual income model predicts and explains stock values better than the model based on discounting short-term forecasts of dividends and cash flows (e.g. [5,7,9,10,11]). Previously, Penman and Sougiannis (1998) stated that if the internal coherence between the three valuation models is violated, the residual income model (RIM) yields more accurate value estimates than the free cash flows model (FCFM) or the dividend discount model (DDM), most likely due to the use of different assumptions [12].

Francis et al. (2000) studied by comparing the accuracy and explainability of dividend, free cash flow, and residual income estimates. The simplifying assumptions was employed to make the relation between the forecasted financial statements and the parameter in the different valuation techniques most likely inconsistent. This study suggested that the residual income model (RIM) is greater than other models [13].

Consequently, Vardavaki and Mylonakis (2007) have investigated the relative power of linear equity valuation model when applied to the food sector in UK. The results of empirical analysis support prior studies, suggests that the combined valuation model which contains both book value and abnormal earnings, is more informative by providing better and more accurate estimations of equity values [14].

\section{Traditional Methodology}

In financial theory, the cost of equity capital is the rate of return that investor expects forward to earn when investing in shares of a company. Which the return is composed of the dividends paid on shares and any change in the stock price of the shares.

Traditionally, the dividend capitalization model (DCM) based estimate of the cost of equity (COE) defines that is equal to the proportion of the expected dividends per share divided by current market value, plus a growth rate of dividends. But this formula cannot calculate the cost of equity for the firms that do not pay dividends for a long time.

$$
C O E=\frac{E(d p s)}{M V}+G(d)(1)
$$

Where,

$$
\begin{aligned}
& E(d p s)=\text { expected dividend per share } \\
& M V=\text { current market value of stock } \\
& G(d)=\text { the growth rate of dividends }
\end{aligned}
$$

The capital asset pricing model (CAPM) was determined a theoretical required rate of return from an asset that is based on the idea of risk aversion. CAPM assumes that when the required rate of return for any risky stock is deflated by its beta coefficient $(\beta)$, the rewardto-risk ratio for an individual stock in the whole market over a time period is equal to the market reward-to-risk ratio. A high level of risk should be accompanied by a corresponding high level of return. The beta coefficient ( $\beta$ ) defines that is the sensitivity of the expected excess returns on an asset to the expected excess market returns (e.g. $[15,16,17])$.

$$
E\left(r_{i}\right)=r_{f}+\beta_{i}\left[E\left(r_{m}\right)-r_{f}\right](2)
$$

Here,

$$
\beta_{i}=\frac{\operatorname{Cov}\left(r_{i, r_{m}}\right)}{\operatorname{Var}\left(r_{m}\right)}=\frac{\operatorname{Cov}_{i, m}}{\sigma_{m}^{2}}(3)
$$

Where,

$$
\begin{aligned}
& E\left(r_{i}\right)=\text { the expected rate of return on a stock } i \\
& r_{f}=\text { the risk-free rate of return } \\
& \beta_{i}=\text { the beta coefficient of a stock } i \\
& E\left(r_{m}\right)=\text { the expected return of the capital market } \\
& E\left(r_{m}\right)-r_{f}=\text { market or risk premium } \\
& \operatorname{Cov}_{i, m}=\text { the covariance of stock } i \text { and its market } \\
& \sigma_{m}^{2}=\text { the variance of stock market }
\end{aligned}
$$

Another definition was presented in the arbitrage theory of capital asset pricing. The arbitrage pricing theory (APT) gives an alternative to the CAPM as a tool to compute the expected rate of returns on stocks, since the APT has more flexible assumption requirements. Whereas CAPM requires the expected return on market, in a while APT uses the expected return on asset and the risk premium of macro factors. That is, APT requires that in the capital market equilibrium the return on a zero-systematic risk portfolio is equal to zero, when the unique effects are independent and diversified away in the large portfolio.

$$
E\left(r_{i}\right)=\lambda_{0}+\lambda_{1} b_{i 1}+\ldots+\lambda_{k} b_{i k}(4)
$$

Where,

$\lambda_{0}=$ the risk free rate of return 
$\lambda_{j}=$ the risk premium related to the $j^{\text {th }}$ common risk factor, when $j=[1, k]$.

$b_{i j}=$ the pricing relationship between the risk premium and the capital asset $i$.

However, many empirical studies cited also indicate some lacking in these capital asset pricing models such as an explanation of the relationship between risk and return. These models cannot explain why sometimes lower beta stocks perhaps provide higher returns. For example, Fischer et al. (1968) suggested that low beta stocks may offer higher returns than the model would predict [18]. Additional empirical tests of the capital asset pricing model in 1972 have the evidences, indicates that the expected excess return on an asset is not strictly proportional to its systematic risk ( $\beta$ ).

Frankel and Lee (1998) have employed the analystbased residual income model to estimate the firm's fundamental values $\left(V_{f}\right)$, and used the resulting value-toprice $\left(V_{f} / p\right)$ ratio to examine issues related to the market efficiency and the predictability of cross-sectional stock returns [19]. Empirical evidence shows that the analyst earnings forecasting are predictable without the relation of $\mathrm{B} / \mathrm{P}$ ratio, firm size, or a firm's market beta. And the predictive power of $V_{f} / p$ can be incremental improved by combining the forecasted earnings growth and the forecasted ROEs relative to current ROEs. In addition, empirical result shown that the efficient market is particularly processing by information available about long-term fundamentals is impounded into the stock price.

As discussed, a small discrepancy in the cost of equity is significantly impacts on the estimated firm value. The error size from missed input is directly relating to the utilized valuation model and its predictability. That meant the mistaken estimate results may cause investors to lose the huge profits, or make them ignore to invest in the excellent profitable firms or common stocks.

The acquisition of the cost of equity capital (COE) is critical important, not less than the origin of its model. The appropriate estimation method of the cost of equity will be stimulates the effectiveness of the valuation model. Some researches related on the equity valuation were ignored or gave little importance to the acquisition of the firm's cost of equity, which is further to be the discount rate or the required rate of return in their experimental models. An improper estimate reasonably causes to misrepresent the actual ability of the accounting based valuation model.

\section{Methodological Proposition}

The high complexity and rare reliability of the traditional estimation of COE are not suitable in practice. Also the traditional estimations disable to adapt for valuing the private firms, divisions, or financial projects which are not traded in the capital market. Especially, the DCM based traditional estimation as shown in the Equation (1), is not effective for the firm that do not pay dividends.

According to the powerful of dividend discount model (DDM), assumes that the current value of common stock
$\left(V_{t}\right)$ is the present value of its expected future dividends (free cash flow to equity) based on all current information available [20].

$$
V_{t}=\sum_{i=1}^{\infty} \frac{E\left(D_{t+i}\right)}{\left(1+r_{e}\right)^{i}}(5)
$$

Where,

$$
E\left(D_{t+i}\right)=\text { the expected dividend during period } t+1 \text {. }
$$

$r_{e}=$ the required rate of return on a stock

RIM or EBO valuation model is algebraically equivalent to the DDM but provide better solution for the equity valuation. Because of the definition assumes a flat term structure of discount rate. Feltham and Ohlson (1992) was explained by using the clean surplus relation, provides a firm's earnings and book value are forecast in a manner consistent with clean surplus accounting [2]. Thus, the Equation (5) can be rewritten as the reported current book equity, plus an infinite sum of discounted residual income.

$V_{t}=B_{t}+\sum_{i=1}^{\infty} \frac{E\left[\left(R O E_{t+i}-r_{e}\right) B_{t+i-1}\right]}{\left(1+r_{e}\right)^{i}}(6)$

Where,

$B_{t}=$ the book equity at time $t$

$E[]=$. the expectation based on information available at time $t$.

$B_{t+i-1}=$ the book value at beginning period $t+1$.

$r_{e}=$ the cost of equity capital

$R O E_{t+i}=$ the after tax return on book equity during period $t+1$.

Feltham and Ohlson explained that infinite-horizontal valuations by the level of accounting conservatism affect the terminal value calculation. The terminal value approaches zero only if the accounting system is not conservative (unbiased). That is, any growth in earnings or cash flows after year $T$ is value neutral.

Notably, this proposition prefers to write abbreviated alphabet as " $k_{t}$ " to denote the cost of equity financing during interest period $t$, which qualifying different to the required rate of return $(r)$ or the cost of equity $\left(r_{e}\right)$ in original model.

The proposition is basically assumes that the cost of equity financing $(k)$ for a firm or common stock reflects from its operating results during constantly interest periods, which these operations have absorbed all systematic factors appropriately, including the systematic risk in the capital market impacts through the variance of its market price (price movements) depending upon the information available.

\subsection{The Cost of Equity Financing $(k)$ for an Asset}

The information in capital market is composed of a firm's fundamental factors related information and other one is combined environmental information. The completed informative situation occurs when the firm officially distributes to public the fundamental information of its operating results which just ending. In reality, where 
normally is not at the ending date of operation. The prospective information defines as the cloudy informative situation, which is processed from other resources available unofficially related to the fundamental of an interesting firm. At wherever is the completed informative situation, the market acknowledges the fundamental value and assesses through the efficient informative infected market value $\left(M V_{t}\right)$ at time, or abbreviate called as fair market value adjust. In finance, the market value of equity sometime called market capitalization. Denotes that the fair market value adjust $\left(M V_{t}\right)$ is possibly adequate, undervalued, or overvalued to its intrinsic value $\left(V_{t}\right)$ at same time.

At the completed informative situation for two positions different, we can calculate the change in worth of a publicly traded company that is equal the difference between the current fair market value adjust $\left(M V_{t}\right)$ and the past fair market value adjust $\left(M V_{t-1}\right)$, at the same considering point. That is, if we are considering at period $t$, it can be determine from the current fair market value adjust $\left(M V_{t}\right)$, minus by the one period future worth of its past fair market value adjust $\left(M V_{t-1}\right)$ which can be manipulated as follows;

$$
\begin{gathered}
M V_{t}-(1+k) M V_{t-1}=\left[B_{t}+\sum_{i=1}^{\infty} \frac{\left(R O E_{t+i}-k\right) B_{t+i-1}}{(1+k)^{i}}\right] \\
-\left[(1+k) B_{t-1}+\left(R O E_{t}-k\right) B_{t-1}+\sum_{i=1}^{\infty} \frac{\left(R O E_{t+i}-k\right) B_{t+i-1}}{(1+k)^{i}}\right]
\end{gathered}
$$

By the way, if we are considering at period $t-1$, the change in equity worth of a public firm can be determine from the one period present worth of its current fair market value adjust $\left(M V_{t}\right)$, minus by the past fair market value $\left(M V_{t-1}\right)$.

$$
\begin{aligned}
& \frac{M V_{t}}{(1+k)}-M V_{t-1}=\left[\frac{B_{t}}{(1+k)}+\sum_{i=1}^{\infty} \frac{\left(R O E_{t+i}-k\right) B_{t+i-1}}{(1+k)^{i}}\right](7 \mathrm{~b}) \\
& -\left[B_{t-1}+\frac{\left(R O E_{t}-k\right) B_{t-1}}{(1+k)}+\sum_{i=1}^{\infty} \frac{\left(R O E_{t+i}-k\right) B_{t+i-1}}{(1+k)^{i}}\right]
\end{aligned}
$$

Market prices which are fluctuating between operating periods are caused by the expectation against the firm's future benefits and its prospective profitability. The conceptual Equation (7a) and (7b) is equivalent. All of summation term in both Equation (7a) and (7b) will be neutralized, and the final calculation of both equation will be the same. The following is arithmetically operated result of both equations which can be displayed in a general form of the cost of equity financing $\left(k_{t}\right)$.

$$
k_{t}=\frac{N I_{t}-\Delta B V_{t}+\Delta M V_{t}}{M V_{t-1}}(8)
$$

Where,

$k_{t}=$ the cost of equity during period $t$

$N I_{t}=$ total net income for period $t$

$\Delta B V_{t}=$ the change in book equity at the end and begin of period $t$

$\Delta M V_{t}=$ the change in fair market value at the end and begin of period $t$
$M V_{t-1}=$ the fair market value for period $t-1$

By take multiply operation by its number of shares into the fraction of Equation (8), which the fair market value or market capitalization divided by total number of shares, is equal to the fair market price. Thus, the estimation of the COE can be represented as below;

$k_{t}=\frac{E P S_{t}-\Delta B V P S_{t}+\Delta P P S_{t}}{P P S_{t-1}}(9)$

Where,

$E P S_{t}=$ net income (earnings) per share at period

$\triangle B V P S_{t}=$ the change in book value per share at the end and begin of period $t$

$\triangle P P S_{t}=$ the change in the fair market price for period $t$ and $t-1$

By using the clean surplus relation (CSR), (e.g. [2,3], [20]) its format requires the change in book value to equal earning minus dividends at the same period $t$. The COE estimate equation can be generated from the Equation (8) and (9) into a term of dividend payout as follows;

$k_{t}=\frac{D_{t}+\Delta M V_{t}}{M V_{t-1}}=\frac{D P S_{t}+\Delta P P S_{t}}{P P S_{t-1}}(10)$

Where,

$D_{t}=$ total dividend payout during period $t$.

$D P S_{t}=$ total dividend paid per share

In financial literature, the dividend payout ratio $(d)$ for a capital asset is equivalent to the percentage of earnings paid to stockholders in dividends each year, then we can represent the COE estimate formula relative to the dividend payout ratio ( $d$ ), which manipulated as follows;

$$
k_{t}=\frac{d * N I_{t}+\Delta M V_{t}}{M V_{t-1}}=\frac{d * E P S_{t}+\Delta P P S_{t}}{P P S_{t-1}} \text { (11) }
$$

The change in a stock's market value divided by its previous market value, or mentioned in other word equally the change in market price divided by its market price of previous period is generally called as the growth rate (or the rate of change) of market value or stock price, respectively. Therefore, all introduced equations for estimating the COE can be rewrite into the terms of growth rate.

$$
\begin{aligned}
k_{t} & =\frac{N I_{t}+\Delta B V_{t}}{M V_{t-1}}+\text { Growthrate of } M V \\
& =\frac{E P S_{t}+\Delta B V P S_{t}}{P P S_{t-1}}+\text { Growthrate of PPS } \\
& =\frac{D_{t}}{M V_{t-1}}+\text { Growthrate of } M V \\
& =\frac{D P S_{t}}{P P S_{t-1}}+\text { Growthrate of PPS } \\
& =\frac{d * N I_{t}}{M V_{t-1}}+\text { Growthrate of } M V \\
& =\frac{d * E P S_{t}}{P P S_{t-1}}+\text { Growthrate of PPS }
\end{aligned}
$$

Additionally, the dividend yield is a financial ratio that indicates how much a firm pays out in dividends relative 
to its market price. In other word, the dividend yield is equal to the firm's total annual dividend payments divided by its market capitalization (market value), or annual dividend per share divided by its price per share. Thus,

$k_{t}=\left(1+D Y_{t}\right) * \frac{M V_{t}}{M V_{t-1}}-1(13)$

And,

$k_{t}=\left(1+D Y_{t}\right) * \frac{P P S_{t}}{P P S_{t-1}}-1(14$

Here,

$D Y_{t}=d_{t} * E Y_{t}(15)$

$E Y_{t}=$ DCover $_{t} * D Y_{t}(16)$

Where,

$D Y_{t}=$ dividend yield for period $t$

$E Y_{t}=$ earnings yield for period $t$

$d_{t}=$ dividend payout ratio for period $t$

DCover $_{t}=$ dividend cover for period $t$.

\subsection{The Cost Of Equity Financing (K) For A Whole Market}

If we take an arithmetical average of all cost of equity capital for each stock in an entire stock market, then we get a stock market's average cost of equity capital. In another form, if we take an arithmetical average of all cost of equity capital for each stock that are the same industry sector in a stock market, then we get that industry sector's average cost of equity capital. From this concept, the following is expressing how to estimate the average cost of equity capital for a capital market or industry sector $\left(k_{t}\right)$ during considering period $t$.

$$
\begin{aligned}
K_{t}(\cdots) & =\frac{1}{N_{t}} \times\left(k_{1}+k_{2}+\cdots+k_{N}\right)_{t} \\
& =\frac{1}{N_{t}} \sum_{i=1}^{N}\left(k_{i}\right)_{t}
\end{aligned}
$$

Where,

$K_{t}(\cdots)=$ a capital market or industry sector's average cost of equity during period $t$

$\left(k_{i}\right)_{t}=$ the cost of equity for a stock $i^{\text {th }}$ in the capital market during period $t$

$N_{t}=$ total number of stocks in a whole market for period $t$.

The quantity $\left(K_{t}\right)$ indicates that how much investor have the current requirement or expectation for gains from their investment in a capital market. The usefulness of this number is using to compare the return expectation level in a whole market to other markets or financial metrics. However, some problems related to the number of stocks and the ability to access statistical data may be trouble in the calculation process.

As mentioned above, to estimate the cost of equity capital for a firm $(k)$ only know its dividend yield and price movement at considering time. Typically, the supervisory authority of capital markets are often publishing only dividend yield and change in market size as the monthly or yearly statistical market data, without total earnings and change in total shareholder's equity for entire market. Therefore, the calculation of $K_{t}$ will be simpler with the reported statistical market data published by the supervisory authority of market.

$K_{t}=\frac{\left(M D Y_{t}^{*} M S_{t}\right)+\Delta M S_{t}}{M S_{t-1}}=\left(1+M D Y_{t}\right) * \frac{M S_{t}}{M S_{t-1}}-1(18)$

Here,

$M S_{t}=M I_{t} \times W_{A N S}(19)$

If the number of shares during considering period is a constant, then the quantity $K_{t}$ is also;

$K_{t}=\left(1+M D Y_{t}\right) * \frac{M I_{t}}{M I_{t-1}}-1(20)$

$K_{t}=M D Y_{t} *\left(\frac{M S_{t}}{M S_{t-1}}\right)+$ Growth rate of $M S(21)$

$K_{t}=M D Y_{t} *\left(\frac{M I_{t}}{M I_{t-1}}\right)+$ Growth rate of $M I(22)$

Where,

$M D Y_{t}=$ market's dividend yield for period $t$

$M S_{t}=$ market size at the end period $t$

$M S_{t-1}=$ market size at the end period $t-1$

$\Delta M S_{t}=M S_{t}-M S_{t-1}=a$ change in market size

$M I_{t}=$ market index at the end period $t$

WANS $_{t}=$ weighted average number of shares in a whole market during period $t$

The propositions explain that the investment expectation from the public firms or assets is associated with an increment in market value, combined with the proportional market value paid in dividends. Or it can be described in other word that a publicly traded firm's required return is related to the increasing in its market price, combined with the proportional market price paid in dividend per share. In conclusion, the interesting in aspect of investors held against a capital market is qualifying the linear relationship that its mathematical format requires the fraction of current market size-to-previous market size which determines the independent variable, is multiplied by the market's dividend yield charged as the slope coefficient, added by the constant growth rate of market size which determines the dependent variable. That is, a whole stock market's weighted average cost of equity financing $\left(K_{t}\right)$ is basically associated with the growth rate of the market index in that stock market or the market size of that stock market, equally.

\subsection{Non-Financing Cost of Equity $(K)$ for a Private Firm}

In the context of stock market, market value is almost different to book value because investors take their expectation into account future potential growth of a particular firm as discussed previously. It is fair to calculate the cost of equity capital for valuing the private firms because we can dispose abnormal expectation from the market impacts to the fluctuation of market price.

Especially, a private firm's market value determined separately in two categories; (a) market value is available 
and not adequate to its book equity for each period $t$, and (b) market value is unavailable or unknown variable. It assumes that is adequate to its book value for each period $t$. For these reasons, by refer to the Equation (8) that the following is expressing how to estimate the cost of equity for valuing a private firm, division or project performance, and asset selection. Since the market values are available for any considering periods, the estimate of the nonfinancing cost of equity $\left(K_{t}\right)$ assumes that the fair market value of equity for an asset is equalize its book value of equity at time, which can be manipulated as follows;

$K_{t}=\frac{N I_{t}-\Delta B V_{t}+\Delta B V_{t}}{B V_{t-1}}=\frac{N I_{t}}{B V_{t-1}}=R O E_{t}(23)$

Where,

$K_{t}=$ a private firm's cost of equity at period $t$

$N I_{t}=$ total net income for period $t$

$B V_{t-1}=$ total book value for period $t-1$

$R O E_{t}=$ the return on equity for period $t$

Meanwhile, the return on common equity measures a stock, project, or asset's profitability performance by revealing how much profit a firm generates with the capital which stockholders have invested in shares of a firm. Notes that the return on common equity is equal to net income after paid preferred dividends, divided by book value of equity at the begin of given period.

\subsection{Degrees of Prospective Expectation on Equity (DPEE) and Market (DPEM)}

In general, the current cost of equity capital $\left(K_{t}\right)$ for a stock is calculating from the sum of total dividends and a change in market value during current period, overall divided by market value at the begin of the given period, or equivalently in other forms. The quantity of COE represents the requirement or expectation of stockholders held against a firm about the potential gains (both or either dividends and increment in market value of equity) from their investment.

In this way, the cost of equity capital $\left(K_{t}\right)$ in the percentage unit (\%) should be illustrate the return expectation level of stockholders whenever are investing in shares of a firm. It defines that the stockholder's degree of prospective expectation on equity (DPEE) is a percentage of the cost of equity capital for a firm.

$$
D P E E_{t}=k_{t} \times 100(\%)(24)
$$

In practice, the quantity of DPEE is very usefulness for the long term. Because of the expectation on a particular stock from the investors is hanging upon the statistical price by comparing its profit performance and dividend payout ability.

Consequently, relying on the same concept that the quantity of COE for a whole capital market (or industry sector) represents respectively the requirement or expectation of stockholders held against that market (or sector) about the potential gains. That is, the capital market's average cost of equity $\left(K_{t}\right)$ in the percentage unit (\%) should be interpret the return expectation level of investors wherever are investing in a capital market or considering sector. It defines that the investor's degree of prospective expectation on market (DPEM) is a percentage of the market's weighted average cost of equity capital.

$\operatorname{DPEM}_{t}=k_{t} \times 100(\%)(25)$

In practice, the quantity of DPEM is also quite powerful for predicting the market index or industry sector indices in the long term. Because of the expectation on a particular capital market from the entire investors are also positively associating with the statistical index or market size by comparing a whole profit performances and integrated dividend payout ability in a particular market.

\subsection{Theory of Intrinsic Worth Valuation Model}

Let $t$ be periods, defines that the $K_{1}$ represents the rate of return on common equity during the first period, the $K_{2}$ represents the rate of return on common equity during the second period, ... and the $K_{t}$ represents the rate of return on common equity during period $t$. The basic equity worth is presenting the book value of equity as $B_{0}$ at base period $t=0$. Thus, the current intrinsic worth $\left(w_{T}\right)$ at current period $t=T$ determines that it is equivalent to a book value at base period $\left(B_{0}\right)$, plus a sum of the change in book value for each period.

$$
\begin{aligned}
W_{T} & =B_{o}+B_{1}+\cdots+\Delta B_{T}=B_{T}=\left(1+k_{T}\right) * B_{T}-1 \\
& =\left(1+k_{T}\right)\left(1+k_{T-1}\right)(\cdots)\left(1+k_{2}\right)\left(1+k_{1}\right) * B_{o}
\end{aligned}
$$

The generalized estimation defines that the current intrinsic worth of common equity is equal the absolute value of the basic equity worth at base period multiplied by the product operation of $1+k$ for each past year.

$W_{T}=\left|B_{O} * \prod_{i=1}^{T}\left(1+k_{i}\right)\right|(26)$

Notably, due to measure the performance of divisions or financial projects, analyst should evaluate through the current intrinsic worth $\left(W_{T}\right)$ by determining the rate of return as $R O E_{i}$ for each past period $t=i$ due to unknown the past market values.

Moreover, if analyst known the past intrinsic worth at period $t$ while $0<t<T$, can estimate the current profitability performance or intrinsic worth from the milestone year which its formats can be represented as follows;

$$
W_{t+T}=W_{t}+\left(W_{t+T}-W_{t}\right)
$$

Hence,

$W_{t+T}=B_{t}+\left|B_{t} * \prod_{i=1}^{T}\left(1+k_{i}\right)\right|(27)$

When $0<t<T$ and $t \geq 1$

Evaluating the cumulative firm worth with the milestone-based intrinsic worth valuation method also classified follows as the information available or unavailable.

Furthermore, if analyst expects forward the rate of return rate current period $T$ for $\bar{i}$ periods as a constant $\bar{k}$ equally. The future intrinsic worth is equal to the $i$ period future worth of book equity at current period. 
$W_{T+i}=B_{T} *(1+\bar{k})^{i}(28)$

The estimate equations as discussed above, mostly like to the money-time relationship. The difference is the future money worth requires the discount rate as the interest rate or inflation rate per period, but the future intrinsic worth is typically requires the discount rate as its return on equity which measures the firm's profitability performance.

The quantity $(1+k)^{i}$ in the Equation (28) is called the single return compound amount factor, which equates to the fraction of the $i$ periods future intrinsic worth and its current intrinsic worth. From this relationship, the future intrinsic worth covering period $(I)$ can be manipulated as follows;

$W_{T+i}=B_{T} *(1+\bar{k})^{i}=W_{T}+W *(1+\bar{k})^{i}$

Then,

$I=\frac{\ln W_{T+i}-\ln W_{T}}{\ln (1+\bar{k})}(29)$

Where,

$I=$ future intrinsic worth covering periods

$W_{T+i}=$ expected future intrinsic worth

$W_{T}=$ current intrinsic worth

$\bar{k}=$ required constant rate of return for next $i$ riods

Although, private firms are not required to provide the information to the public, it is quite difficult to determine their financial consistency. But the usefulness of this estimate method for a firm's cost of equity which its formula requires only some accounting number, and then analyst can find its core worth. The intrinsic worth is provided from the firm's quantitative information such as financial statement and its financial ratios. While the extrinsic worth is evaluated from the firm's qualitative information such as governance, business model, knowhow and human resources, etc.

In economics, inflation is a rise in the general price level of goods and services in an economy over a period of time, and subsequently reflects decay in the purchasing power of currency. The main cause of inflation is excessive growth in the money supply. According to the quantity theory of money, states that the quantity of money and price levels of goods increase at the same rate in the long term. If assumes that the velocity of money and the amount of transactions in the economy are basically constants, increasing the money supply will lead to a proportional increment in the average prices (inflation). In contrast, deflation is a decrease in the general price level of goods and services which occurs when the inflation rate becomes a negative value. It is primarily caused by a reduction in the velocity of money and/or the amount of money supply. Deflation can be caused also by a decrement in the expenditure of government, personal or investment. It is summarized that the inflation reduces the worth of money over time but the deflation increases the worth of money.

To include the impacts of inflation or deflation where $p_{t}$ represents the actual rate of inflation (value-decayed) or deflation (value-added) during each past given period $t$, thus the multi-return factors based intrinsic worth estimate of an objective firm or project will be shown as follows;

$W_{T}=\left|B_{O} * \prod_{i=1}^{T}\left(1+k_{i}+p_{i}\right)\right|(30)$

Where,

$B_{O}=$ book value of equity at base period $T=0$

$k_{i}=$ rate of return for any period $i$

$p_{i}=$ rate of inflation (-) or deflation (+) for any period it

Therefore, analyst can employ this formation to value the firms or assets with concerning the purchasing power of money through its cumulative firm worth. Reminds that the rate of return in this equity valuation is the cost of equity which separately follows the information of market value is available or unavailable.

\section{Conclusions}

The discussed estimations were expressing in the various forms of accounting variables which can be employed to estimate the COE for valuing toward the intrinsic firms worth. In theoretical, its calculated result should be equivalent for each equation. Although, the equality of each formulas perhaps impossible in practical because the calculation procedure generates small tolerant for each formulas since effecting from some unstable variables in accounting operation such as the dilution in earnings or number of shares, dividends paid to share outstanding only, sometime dividends paid higher than its profitability, etc.

However, Thanakornn (2013) shown empirical evidences that these small tolerant are acceptable and generally all formulas are interchangeable. Because of all formulas for estimating the cost of equity capital have very small tolerant (approaching to zero) that some case may be not different, if an analyst determines the decimal point limited only a few positions [21]. Additionally, empirical tests strictly support this assumption when the investors are still investing in a firm that is growing in profitability but has never paid dividends for the long term such as Apple, Baidu, Google, Berkshire, and so on. Because of those companies make further efficiency gains (higher return on operating income) with competency since no dividend policy. As results, stockholders are earning from an increment in the worth of company (growth in market value).

The study found empirical evidences that the efficient informative market exists and the fluctuation of market price affects from the uncompleted fundamental information and the uncertainty of the combined environmental information. The tests found that the movement of the market index is directly proportional to the trendy direction of the primary indices, include the movement of stocks that are worth less should be volatility than the stocks that are worth more, in general liquidity.

In application, this literature is to introduce the method of intrinsic worth valuation which one is associating to the cost of equity financing (COE) when the market values of that firm are available, and otherwise is based upon the return on equity (ROE) when the market values are 
unavailable. Therefore, the intrinsic worth valuation can also be applied for estimating the other assessments such as measuring the performance of divisions, profitable projects, and assets.

\section{References}

[1] Frank, K. R. \& Keith, C.B. Investment Analysis and Portfolio Management, 7E. Thomson, 2003.

[2] Olhson, J.A., \& Feltham, G. Valuation and Clean Surplus Accounting for Operating and Financial Activities. Contemporary Accounting Research, 1992.

[3] Ohlson, J.A. Earnings, Book values and Dividends in Security Valuation. Contemporary Accounting Research, 11. 661-687. 1995.

[4] Myers, James. Implementing residual income valuation with linear information dynamics. The Accounting Review, vol. 74(1): 1-28. 1999.

[5] Dechow, Patricia M., Hutton, Amy P., \& Sloan, Richard G. An Empirical Assessment of the Residual Income valuation Model. Journal of Accounting and Economics, Vol.26: 1-34. 1999.

[6] Morel, Mindy. Endogenous Parameter Time series Estimation of the Ohlson Model: Linear and Nonlinear Analyses. Journal of Business Finance and Accounting, vol. 30(9-10): 1341-1362. 2003.

[7] Beaver, William H. Perspectives on recent capital market research. The Accounting Review, vol. 77(2): 453-474. 2002.

[8] Callen, Jeffrey L., \& Segal, Dan. Empirical tests of the FelthamOhlson model (1995). Review of Accounting Studies, vol. 10(4): 409-429. 2005.
[9] Plenborg, T. Firm Valuation: Comparing the Residual Income and Discounted Cash Flow Approaches. Accounting and Business Research, vol. 18: 303-318. 2002.

[10] Victor, L.B. Accounting Based Valuation Methods, Determinants of Market-to-Book Ratios, Implications for Financial Statements Analysis, Working Paper, University of Michigan, 1994.

[11] Victor, L.B. The Feltham-Ohlson Framework: Implications for Empiricists. Contemporary Accounting Research, 11. 1995.

[12] Penman, S.H. \& Sougiannis, T.. A Comparison of Dividend, Cash flow, and Earnings Approaches to Equity Valuation. Contemporary Accounting Research, 343-383. 1998.

[13] Francis, J., Olsson, P. \& Oswald, D. Comparing the Accuracy and Explainability of Dividend, Free cash flow and Abnormal Earnings Equity Value Estimates. Journal of Accounting Research, 38. 2000.

[14] Vardavaki, A. \& Mylonakis, J. Empirical Evidence on Retail Firms' Equity Valuation Models. International Research Journal of Finance and Economics, 7. 2007.

[15] Harry, M. M. Portfolio Selection: Efficient Diversification of Investments. John Wiley \& Sons, 1959.

[16] William, F.S. A Simplified Model for Portfolio Analysis. Management Science, 9. 1963.

[17] William, F.S. Capital Asset Prices: A Theory of Market Equilibrium Under Conditions of Risk, Journal of Finance. 1964.

[18] Fischer, B., Michael, C.J., \& Myron, S. The Capital Asset Pricing Model: Some Empirical Tests. New York: Praeger Publishers, 79121. 1972.

[19] Frankel, R. \& Lee, Charles M. Accounting Valuation, Market Expectation, and Cross-sectional Stock Returns. Journal of Accounting and Economics, 25. 283-319. 1998.

[20] Charles, M.C. Lee. Measuring Wealth. CA Magazine, 32-37. 1996.

[21] Thanakornn, P. Core Ingredient Corporate Wealth Measurements. Beijing Institute of Technology: Dissertation, 2013. 